\title{
DIALOGANDO EN LA COCINA
}

\author{
Thérèse Bouysse-Cassagne ${ }^{1}$
}

\begin{abstract}
He sido feliz con mis insuficiencias porque sentía el Perú en quechua y en castellano. ¿Y el Perú qué? Todas las naturalezas del mundo en su territorio, casi todas las clases de hombres. Es mucho menos extenso pero más diverso como fue la Rusia Antigua (J.M. Arguedas, Último Diario)

En tiempos del rey español, la tierra era del rey español y también la vida (J.M. Arguedas, Todas las Sangres)
\end{abstract}

En la introducción de La organización Económica del Estado Inca, John Murra escribía "Se publica esta tesis 22 años después de ser presentada y defendida en el departamento de antropología de la Universidad de Chicago en 1955. No fue escrita para ser publicada, era un documento personal, en el sentido en que un poema o una carta pueden ser comunicaciones destinadas a una sola persona o un grupo restringido. Aunque no lo parezca esta tesis tiene muchas de las características de un diario personal: se trataba de una comunicación entre el autor y su psicoterapeuta. Su publicación antes de 1970 no era soportable".

Su tesis iba dedicada a Saúl B. Newton, oficial del batallón 60, 15 brigada, Ejército Republicano Español y director del Instituto Sullivan de psicoanálisis de Nueva York. En pocas palabras tenemos resumida por el mismo autor su manera de vincularse en aquel entonces con su obra-que no consideraba bajo el prisma de un trabajo universitario "a secas"- sino que lo definía a través de vínculos afectivos y de procesos inconscientes, en gran parte dolientes.

Quien de nosotros no percibió efectivamente que cuando hablaba de Chuchuyari hablaba de un familiar suyo, o cuando mencionaba a "los señores" étnicos chupaychus o lupacas los trataba como a los vecinos de la puerta de al lado. Si se refería a Polo (raras veces decía Polo de Ondegardo) o al Doctor Barros de San Millan (decía Barros) su voz tomaba un tono tajante y admirativo, como si hablara de grandes políticos actuales que entendieron los Andes y con quienes entretenía un diálogo permanente.

Detrás de esta familiaridad -perceptible en el vocabulario que usaba en todas sus clases ( $\mathrm{y}$ aun más evidente en castellano que en su francés más formal)-no sólo había muchísimo trabajo sino que de cierta forma uno se daba cuenta que John se refería a aquella historia de reinos, señores, estados como un militante (hablaba de ellos como el adolescente que había pertenecido a las juventudes comunistas de Bucarest y el combatiente en las brigadas internacionales que fue). Pero, sobre todo, más allá de la historia que escribía, su trabajo le permitía-como en el proceso analítico- reconstruir su propia historia, de la misma manera que cada mañana se aplicaba a escribir sus sueños de la noche anterior con mucho esfuerzo de memoria y mucha impaciencia.

Durante los años que estuvo en París asistí a todas sus clases y él pasó muchos fines de semana en nuestra casa. Una de nuestras primeras charlas fue sobre Arguedas. Había escrito sobre este autor, para un diploma, que influenció definitivamente mi recorrido de andinóloga e hizo que empezara de nuevo a estudiar historia y antropología, pero nunca llegué a conocer a Arguedas en persona. Me emocionaba lo que John me contaba de él y de esta manera empezamos a hablar a menudo. Nuestras discusiones sobre Arguedas, Cataluña, el franquismo, los Andes, el psicoanálisis, la antropología, mezclando experiencias intelectuales y vivencias, solían acabar en la cocina.

En una de aquellas ocasiones fue cuando le escuché decir la palabra mamaliga que significa polenta, la única palabra que le oí pronunciar en rumano, fuera de los momentos en los que se expresaba con su hermana. Dos o tres veces nos regaló a los amigos con lo que él consideraba un festín: la pierna de cordero con cacha. Era toda una

1 Directrice de Recherche au CNRS, París, France. therese.bouysse.cassagne@gmail.com 
ceremonia ritual. Como a sus clases, no había que llegar tarde a la mesa. No sufría porque el plato se enfriara, porque él era quien servía con autoridad a cada uno de los comensales.

En París, a la hora del almuerzo buscaba lo que llamaba "los restaurantes de tinta violeta". Tardé un tiempo en entender lo que significaba para él esta fórmula y su insistencia para comer en aquellos restaurantes. Simplemente eran los pocos establecimientos que todavía tenían un menú escrito a mano y que ofrecían una comida relativamente sencilla y tradicional con platos del día algo caseros. En la calle des Rosiers, le enseñé la tienda Fynkelstein, un "traiteur" donde compraba a menudo los platos de Europa central que le gustaban.

No usaba agenda, de su carpeta marrón solía sacar una hoja de papel cuadriculado donde cada día de la semana iba programado con lápiz. Al fin de la semana, dicha hoja tenía aspecto de bandoneón, por ser doblada día tras día escondiendo de esta forma la línea del día anterior. A pesar de sus numerosas salidas, de los restaurantes de tinta violeta, de sus citas amistosas o de trabajo con todos nosotros, que inscribía en esta hoja, no se sentía totalmente a gusto en París. Se quejaba del frío y de la nieve de Cornell, pero en la primavera añoraba las peonías de su jardín o soñaba con irse a vivir a Arica. Siendo un tema tan recurrente y dolido el de donde establecería su futura casa, desde el primer día en que lo conocí tuve el sentimiento de que el exilio era su verdadero reino.

Si a través de sus vínculos con la comida se percibía todavía la longevidad de sus lazos con sus raíces europeas, al opuesto era palpable su voluntad de construir gracias al trabajo una comunidad andinista de investigadores que de cierto modo consideraba como su familia: una familia extensa, muy dispersa y cosmopolita que juntara esfuerzos distintos y disciplinas diversas en la que se mezclaban para él, el pasado y el presente, los nombres andinos del XVI con los de los andinistas del XX: Cari, Franklin, Jorge, Cusi, Frank, Cutimbo, Marti... y en París llegó a inventar el apodo de "damas andinas".

Esta red de relaciones a larga distancia se materializaba a través de contactos y publicaciones y fue de esta forma, más sus discusiones con Wachtel, que nació el número de Anales de 1978. En aquellos años me acuerdo que corrigiendo el segundo capítulo de mi tesis que trataba de la existencia de reducciones incaicas y cambios de asentamientos en torno al Titicaca con desplazamientos de poblaciones Urus, él me puso inmediatamente en contacto con "Hyslop" que estaba trabajando en la región Lupaca escribiendo también lo que sería su futura tesis.

Para los jóvenes que éramos en aquel entonces era muy importante romper con la soledad de la investigación que era la nuestra y sentir que compartíamos el mismo interés que otros. John, que era muy consciente de la importancia de su papel de mediador, encontraba, probablemente, de esta manera también un lugar simbólico donde situarse mientras que cuestionaba constantemente el lugar donde deseaba vivir.

Él aficionaba especialmente los balances de investigación que no sólo marcara el avance colectivo que anhelaba sino que designara las tareas que quedaban por hacer. En el prefacio del libro de Arguedas Las Comunidades de España y del Perú escribía efectivamente a propósito de este autor: "nos damos cuenta de lo claras que eran sus prioridades, qué sentido tenía lo que era urgente en los Andes".

A menudo en sus clases mencionaba lo que él consideraba como "prioridades" "urgencias", refiriéndose de modo implícito a otras tareas como menos urgentes, o simplemente inútiles. Era claro lo que él consideraba como urgente y bueno.

No todos los adelantos eran de su agrado y se sentía defraudado cuando uno de nosotros se alejaba de lo que él había proyectado. Sin embargo, como bien sabemos, los avances de la investigación difícilmente se pueden medir a priori en términos de rumbo y menos aun cuando pensamos como John que para cada uno de nosotros investigar es un acto que se sitúa en el interfaz entre la historia personal y la Historia.

Recordando aquellos años, cuando nos fijamos en la manera como los estudios sobre la región lacustre del Titicaca se adelantaron, no cabe duda que la influencia de Murra fue fundamental.

Los primeros en producir un discurso sobre lo que él llamaba los líderes étnicos, su lugar en las sociedades incaicas y coloniales fueron los cronistas y obviamente los «señores indígenas» fueron descritos desde la perspectiva del Conquistador. Las "estructuras andinas del poder" fueron interpretadas en las crónicas en términos de la Europa medieval: "reino", "provincia", "señorío", "imperio", "gobernador", "señor" y dado que el centro del sistema político colonial era el Rey es bastante 
lógico, por lo tanto, que los españoles asimilaran toda estructura política con su idea de "reino". Si durante mucho tiempo las crónicas constituyeron las fuentes que permitieron la reconstrucción del pasado andino no se les aplicó una verdadera crítica histórica. El mismo Rowe en el Handbook of South American Indian analiza el orden incaico a partir de una lectura acrítica de los cronistas. Y es esta visión de los kuraka como parte del sistema administrativo incaico que prevaleció durante la primera mitad del siglo XX (Rowe 1946).

Murra no cambió las palabras usadas en las crónicas -acordémonos de los Lupacas, como "reino aymara"- sino que las desvió de su sentido inicial intentando caracterizar las formaciones políticas precoloniales en base a su funcionamiento, y pensando en el de los reinos africanos de los que hablaba tan a menudo. Este cambio de perspectiva produjo de hecho un cambio de mirada sobre los textos.

Dejando a un lado el debate sobre los modos de producción prehispánicos y coloniales, Murra retomó la terminología elaborada por Karl Polanyi para caracterizar los mecanismos de la economía (Polanyi et al. 1976 [1957]). A partir de él, la reciprocidad y la redistribución, junto con el control vertical de un máximo de pisos ecológicos, dieron las pautas a mucho de los futuros trabajos (Murra 1999 [1955], 1975) ${ }^{1}$.

En torno a la estructura política de los Inca, sugería que el interés del investigador debería estar puesto en dilucidar las relaciones establecidas entre los grupos étnicos conquistados y el poder estatal cusqueño. Dentro de esta perspectiva, el estudio de los kuraka andinos se volvía crucial, toda vez que ocuparon esa posición intermedia entre los Estados conquistadores y los miembros de sus ayllu. Aquí es donde Murra rescata el carácter redistributivo de la autoridad del líder étnico, a través del cual, según él, el Estado incaico lograba reproducir sus bases de poder.

Dejó de lado, sin embargo, los procesos de segmentación socio-territorial acarreados por la colonia así como las visiones divergentes de la naciente elite colonial y su ambigüedad aunque muchos documentos coloniales se hicieran eco de ella.

Su visión del mundo andino ha sido criticada, a veces tachada de esencialista, pero para entender el paso adelante que significaron sus estudios en aquel entonces conviene más que todo resituarlo en lo que era el contexto de estos estudios desde Prescott hasta Rowe y considerar los nuevos aportes que fueron los suyos (Martínez Cereceda 2004; Poole 1992; Salomon 1982).

Desde fines de la década de 1950 hemos asistido al acercamiento de varios programas de investigación, de tal modo que en la actualidad es prácticamente imposible pensar en una Historia precolonial y colonial sin las herramientas de la antropología o de la arqueología.

Desde el punto de vista de la metodología, la renovación tuvo que ver con la utilización de un nuevo conjunto de fuentes, de tipo administrativo y judicial, originadas en la burocracia colonial. Me refiero a visitas, revisitas, registros de escrituras públicas, pleitos y juicios, padrones de indios, informes de funcionarios estatales, memoriales, probanzas de servicios y méritos presentados por los propios kuraka.

El panorama cambió radicalmente con la publicación de dos visitas pretoledanas: la de Garci Diez de San Miguel a Chucuito 1567 por Waldemar Espinosa, y la de Iñigo Ortiz de Zúñiga a León de Huánuco 1562, proyecto interdisciplinario bajo la dirección de Murra (Diez de San Miguel 1964 [1567]; Ortiz de Zúñiga 1967-1972 [1562])². En la visita de Chucuito escribió "Una apreciación etnológica de la visita", artículo que anticipaba su famoso trabajo sobre las formaciones económicas del mundo andino titulado "Un reino aymara en 1557". La situación privilegiada de los lupaqa estaría dada, según él, por haber quedado fuera del sistema de encomiendas tras haber sido "puestos en cabeza de Su Majestad", por el control que ejercieron sobre los recursos de ambas vertientes del altiplano (costa pacífica y valles orientales) y por el poder de sus "señores étnicos" principales, Martín Qhari y Martín Kusi de Chucuito (poder que pronto comenzarían a perder a favor de otros mallku de menor jerarquía) (Murra 1968, 1972).

La incorporación de las visitas y demás papeles de la administración colonial como fuentes permitió repensar y reinterpretar el pasado desde una aproximación diferente y prácticamente todos los estudios de etnohistoria ulteriores se inspiraron de éste.

Este trabajo abrió campo a otros más, citaremos tan solo algunos:

La tesis de John Hyslop sobre los asentamientos lupaqa. Los trabajos de Franklin Pease y Gabriel Martínez que indagaban también cuestiones 
relacionadas con el patrón de asentamiento lupaqa preincaico y las transformaciones a partir de la dominación incaica, desde otras fuentes documentales.

Sobre las transformaciones del "reino lupaqa" hasta mediados del siglo XVII, tenemos los trabajos de Pease, Del Tawantinsuyu..., cap. 3.

Gabriel Martínez, "Espacio lupaqa: algunas hipótesis de trabajo", en Amalia Castelli, Marcia Koth de Paredes y Mariana Mould de Pease (comps.), Etnohistoria y Antropología Andina, Segunda Jornada del Museo Nacional de Historia, Lima, 1981, pp. 263-280.

de Thierry Saignes y Carmen Beatriz Loza, "El pleito entre Bartolomé Qhari, mallku de los lupaqa, y los corregidores de Chucuito (1619-1643)", en Historia y Cultura, 5-6, La Paz, abril-octubre de 1984, pp. 29-48 y 183-193.

Y las Críticas al modelo de Murra en Carlos Sempat Assadourian, "Intercambios en los territorios étnicos entre 1530 y 1567, según las visitas de Huánuco y Chucuito.

Así como los trabajos de Olivia Harris, Brooke Larson y Enrique Tandeter (comps.), La Participación Indígena en los Mercados Surandinos. Estrategias y Reproducción Social, siglos XVI-XX, CERES, La Paz, 1987, pp. 65-110.

En su fecundo trabajo sobre los Lupacas Murra se interesó en la estratificación social del grupo y a partir del caso de los urus en la multietnicidad también.

Mi trabajo sobre los idiomas lacustres (in David. N. Cook, Visita de Toledo 1975), mi ulterior trabajo sobre los Aymara escrito en 1980) así como los numerosos estudios de Wachtel sobre los Uru (en particular Le retour des Ancêtres 1990) fueron influenciados por su lectura.

En aquellos años, desde la arqueología, también se empezó a estudiar el liderazgo étnico. Katherine Julien, alumna de Rowe, escribía su tesis sobre Hatunqolla.

Luis Lumbreras y Hernán Amat se propusieron diagramar una secuencia cronológica para el este y el norte del lago Titicaca, poniendo el énfasis en las transformaciones acaecidas por el surgimiento, consolidación y posterior crisis de Tiwanaku. Así, el proceso de desintegración de esta entidad estatal habría dado lugar a un "vacío de poder", a un reacomodamiento poblacional y a una situación de conflictividad permanente en torno al control de las rutas de circulación, características del período Intermedio Tardío traducidas en la proliferación de estilos cerámicos locales y regionales (Lumbreras y Amat 1968; Lumbreras 1974).

Quedaba por entender cuáles eran los grupos étnicos que ocupaban el conjunto del espacio lacustre y relacionar esta ocupación con los padrones de asentamiento en las distintas épocas. Resituar la historia Inca entre el periodo de hegemonía de los señoríos lacustres y la conquista, pero trabajar también el periodo anterior relativo a la caída de Tiwanaku ya que se suponía que eran las mismas poblaciones que habían atravesado los siglos. Algunos de nosotros nos hemos ocupado en esta tarea, pero había y sigue habiendo trabajo sobre estos temas para varias décadas todavía.

A partir de la década de los años 1980 y hasta 1991 la investigación tomó nuevos rumbos. Los geólogos y limnólogos franceses con un programa del ORSTOM se interesaron en comprender los cambios de niveles lacustres cuyos resultados fueron publicados en 1992 por C. Dejoux y A. Iltis en Lake Titicaca, a Synthesis of Limnological Knowledge. Desde entonces nuestros conocimientos en materia de historia del clima no cesaron de progresar.

En 1993 salía el libro de Kolata sobre Tiwanaku Retrato de una Civilización Andina ... era el comienzo de estudios de más larga duración que intentaban incluir en su reflexión la historia del paisaje, del clima y del medio ambiente lacustre. Este empezaba a ser mejor conocido gracias a los trabajos de arqueólogos como Browman, Denevan o Concklin, mientras que trabajos empíricos de interés arqueológico como los de Erickson sobre los campos de cultivos daban nuevos resultados...

Hubo que esperar casi 10 años más para que los historiadores junto con los arqueólogos empezaran a tomar en cuenta las especificidades del biotopo lacustre y relacionarlas con la historia de los grupos del Titicaca, pienso especialmente en los trabajos de Pärssinen, sobre los Pacajes (Caquiaviri y la Provincia Pacasa, La Paz 2005) y de los que Pärssinen realizó con Siiriäinen, "Inka-style ceramics and their chronological relationship to the Inka expansion in the southern lake Titicaca area (Bolivia)", en Latin American Antiquity, 1997 (editado en castellano en Pärssinen, Caquiaviri..., cap. VI).

Últimamente las investigaciones arqueológicas que realizó Korpisari, alumno de Pärssinen en la isla de Pariti, y su tesis recientemente publicada, sostenida en 2006 titulada Death in the Bolivian High Plateau que demuestra una continuidad poblacional y una gran diversidad de grupos -selváticos incluso-desde 
el Tiwanaku en la cuenca lacustre, constituyen un aporte arqueológico de primera importancia para el adelanto de nuestras investigaciones.

Por otro lado, a partir del análisis del estilo cerámico denominado Inca-Pacajes Pärssinen sugiere la existencia de contactos entre el sur del lago Titicaca y la región cusqueña en torno al siglo XIV, lo cual estaría dando cuenta de interacciones culturales, previas a la conquista efectiva del Tawantinsuyu (Pärssinen y Siiriäinen 1997) ${ }^{3}$. ¿Qué motivó estos contactos y por qué se dieron? ¿Cómo se explica entonces la territorialidad incaica? ¿Cómo explicar el conjunto de modificaciones generadas por la expansión del Tawantinsuyu sobre las diversas sociedades del lago? ¿Fue la nueva territorialidad negociada, resistida o consensuada? (Julien 1998). Muchísimas nuevas preguntas quedan por plantearse que se sitúan en la prolongación de las que se planteaba John Murra.

\section{Referencias Citadas}

Alberti, G. y E. Mayer

1974 Reciprocidad andina: ayer y hoy. En Reciprocidad

e Intercambio en los Andes, compilado por G. Alberti y

E. Mayer, pp. 13-33. IEP, Lima.

Arguedas, J.M.

1971 ¿Último Diario? En El zorro de arriba y el zorro de abajo. Losada, Buenos Aires.

1964 Todas las Sangres. Losada, Buenos Aires, o Editorial Biblioteca Peruana, Lima.

Block, D.

1999 Thirty years of visitas de indios, an annotated bibliography. Versión digital en http://www.library.cornell.edu/ colldev/davidpubmurravisita.html.

2000 "Treinta años de visitas de indios, una bibliografía anotada", reeditado en Anuario del Archivo y Biblioteca Nacionales de Bolivia pp. 575-601, Sucre.

Dejoux, C. y A. Iltis, editores

1992 Lake Titicaca, a Síntesis of Limnological Knowledge. Kluwer Academic Publishers, Dordrecht.

Díez de San Miguel, G.

1964 Visita Hecha a la Provincia de Chucuito en el año 1567. Edición de Waldemar Espinoza Soriano. Casa de la Cultura del Perú, Lima.

Ortiz de Zúñiga, I.

1967-1972 Visita de la Provincia de León de Huánuco en 1562. Edición de John V. Murra, 2 tomos. Universidad Hermilio Valdizán, Huánuco.

Julien, C.J.

1998 Los curacazgos de Chala y Ocoña. En 50 Años de Estudios Americanistas en la Universidad de Bonn, editado por S. Dedenbach-Salazar Sáenz, C. Arellano Hoffmann, E. König y H. Prümers. Bonner Amerikanistische Studien 30, pp. 495-511. Anton Saurwein.

Lumbreras, L.G.

1974 Los reinos post-Tiwanaku en el área altiplánica. Revista del Museo Nacional 40:55-85. Lima.
Lumbreras, L.G. y H. Amat

1968 Secuencia arqueológica del altiplano occidental del Titicaca. Actas y Memorias del $37^{\circ}$ Congreso Internacional de Americanistas, tomo 2, pp. 75-106, Buenos Aires.

Martínez Cereceda, J.L.

2004 La construcción de identidades y de lo identitario en los estudios andinos (ideas para un debate). América Indígena 60:6-20.

Murra, J.V.

1968 Prefacio. En Las Comunidades de España y del Perú, editado por J. M. Arguedas, UNMSM, Lima.

1975 Formaciones Económicas y Políticas del Mundo Andino. IEP, Lima.

1999 [1955] La Organización Económica del Estado Inca. Siglo XXI, México.

1968 Un reino aymara en 1567. En Formaciones..., pp. 193229 y $59-115$.

1972 El control vertical de un máximo de pisos ecológicos en la economía de las sociedades andinas. En Formaciones..., pp. 193-229 y 59-115.

Pärssinen, M. y A. Siiriäinen

1997 Inka-style ceramics and their chronological relationship to the Inka expansion in the southern lake Titicaca area (Bolivia). Latin American Antiquity 8:255-271.

Polanyi, K., C.A. Arensberg y H.W. Pearson 1976 [1957] Comercio y Mercado en los Imperios Antiguos. Labor, Barcelona.

Poole, D.

1992 Antropología e historia andina en los EE.UU.: buscando un reencuentro. Revista Andina 19:209-245.

Rowe, J.H.

1946 Inca culture at the time of the Spanish conquest. En Handbook of South American Indians, editado por J.H. Steward, Tomo 2, pp. 183-330. Smithsonian Institution, Washington. Salomon, F.

1982 Andean ethnology in the 1970's: A retrospective. Latin American Research Review 17:75-128. 


\section{Notas}

1 Veamos una formulación de esta especificidad de "lo andino": "La tesis principal que planteamos, resumiendo los trabajos de John V. Murra, y posteriores esclarecimientos y desarrollos de Nathan Wachtel, es que los principios fundamentales de la organización socio-económica de las sociedades andinas eran la reciprocidad, la redistribución y el control vertical de la ecología" (Alberti y Mayer 1974:15).
2 Sobre el trabajo con visitas como renovación metodológica en la etnohistoria andina, ver también David Block (1999), reeditado en castellano (2000).

3 Editado en castellano en Pärssinen (Caquiaviri..., cap. VI).

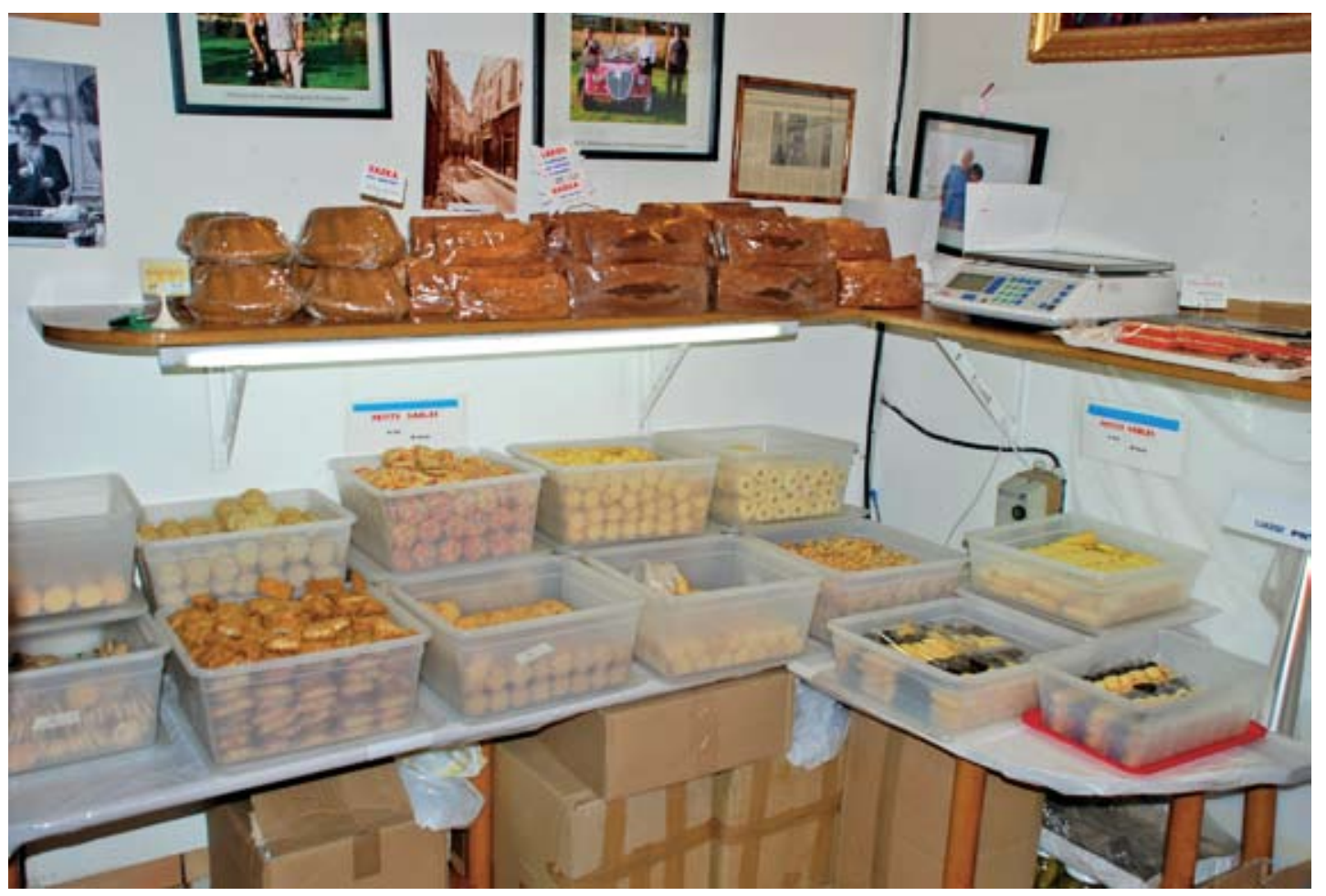

